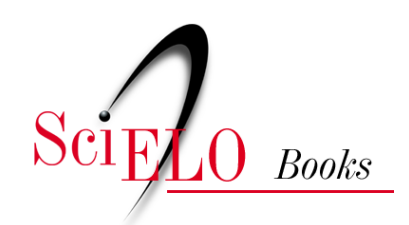

\title{
Concepción del adulto mayor
}

\author{
Carol Iván Abaunza Forero \\ Mónica Alexandra Mendoza Molina \\ Paola Bustos Benítez \\ Giovanny Paredes Álvarez \\ Karla Vanessa Enriquez Wilches \\ Andrea Carolina Padilla Muñoz
}

\section{SciELO Books / SciELO Livros / SciELO Libros}

ABAUNZA FORERO, C.I., MENDOZA MOLINA, M.A., BUSTOS BENÍTEZ, P., PAREDES ÁlVAREZ, G., ENRIQUEZ WILCHES, K.V., and PADILHA MUÑOZ, A.C. Concepción del adulto mayor. In: Adultos mayores privados de la libertad en Colombia [online]. Bogotá: Editorial Universidad del Rosario, Instituto Rosarista de Acción Social - SERES, 2014, pp. 60-98. ISBN 978958-738-532-8. https://doi.org/10.7476/9789587385328.0007.

All the contents of this work, except where otherwise noted, is licensed under a Creative Commons Attribution 4.0 International license.

Todo o conteúdo deste trabalho, exceto quando houver ressalva, é publicado sob a licença Creative Commons Atribição $\underline{4.0}$.

Todo el contenido de esta obra, excepto donde se indique lo contrario, está bajo licencia de la licencia $\underline{\text { Creative Commons }}$ $\underline{\text { Reconocimento } 4.0 .}$. 


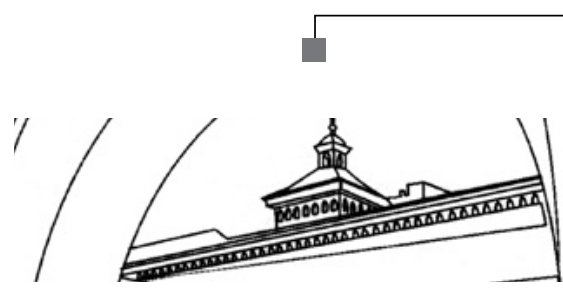




\section{Concepción del adulto mayor}




\section{Generalidades}

El término AM es un eufemismo para disimular la realidad de la vejez, considerada, de por sí, como un estigma, un estamento costoso e inútil (Gainzo Vicente, 2009). No obstante, a través de los siglos se ha valorado como una etapa de respeto y de sabiduría que merece más que consideración.

Desde la perspectiva jurídica, se puede afirmar que es la propia ley, como su intérprete autorizada, la que busca definir al AM (Corte Contitucional, 2010), sin que su conceptualización relativa a la tercera edad resulte forzosamente clara y aceptable, por lo que también se considera que las personas que por sus características fisiológicas, psicológicas y mentales, que no necesariamente convergen en una edad determinada, son las que revelan una disminución en la integridad de su ser, condición que demanda asistencia, cuidado, consideración, protección y solidaridad no solo de sus semejantes, sino de manera especial del Estado a través de la ley. Los jubilados y no jubilados deben contar con estilos de vida adecuados y con la garantía de políticas que opten por mejorar su calidad de vida, disminuir efectivamente los gastos en salud pública y renovar las relaciones familiares y el entorno comunitario. El AM requiere que se le asigne un rol en la sociedad; el final del tiempo no puede ser un espacio exclusivo para la desocupación, el dolor, la enfermedad, la angustia y la orfandad, en espera de la muerte. Si el menor no se puede autosostener, requiere de protección y cuidado frente a su condición de vulnerabilidad; la misma protección y cuidado se le debe dispensar al AM que se encuentre en la misma situación.

Se estipula que los AM son aquellas personas que, debido al proceso de los años, se hallan en una etapa de cambios a nivel físico y psicológico, y dentro de la comunidad se les debe dar condiciones y garantías para la efectividad de los derechos económicos y sociales, ya que requieren de cuidados especiales durante el proceso de envejecimiento (Dueñas, 2011). Así las cosas, se debe propender por el reconocimiento del AM como un eje fundamental de la sociedad en la relación con el Estado, la familia, la educación, el bienestar, la recreación, el trabajo, y comprender que sus cambios obedecen a una etapa natural e inevitable que no debe ser burlada y que no puede ser excusa para discriminarlos o desarraigarlos de su entorno, familia, 
trabajo y hasta del mismo Estado, pues por un lado se legisla a favor de esta población, pero, por otro lado, son excluidos y eliminados del conjunto de la fuerza de producción, de trabajo o de la población considerada como "útil".

Establecer en la actualidad un término que identifique lo que comúnmente conocemos como viejo, anciano o persona de edad, nos remite necesariamente a los logros conceptuales que desde diversas disciplinas como las llamadas ciencias médicas y las ciencias sociales se han construido. La determinación en relación con la edad, tiene diversos componentes que van desde consideraciones según el nivel de bienestar de la población, hasta los avances médicos y de participación social. [...] Los organismos mundiales, ubican a esta población entre los 60 o más años. [...] En abril de 1994 la Organización Panamericana de la Salud decidió emplear el término adulto mayor, que abarca una visión integral, interdisciplinaria y holística. (Universidad Libre, s. f.)

Si bien concordamos en que el envejecimiento no se puede definir en términos de edad, puesto que en él influyen diversidad de variables como el estilo de vida, la condición socioeconómica, los hábitos de vida saludables, la ocupación y las condiciones de salud, entre otras, y que por tal motivo es difícil establecer una edad única para hablar de AM, en esta investigación se abordó la población de 60 años y más, clasificación que ha sido aceptada por la OMS.

La vejez no es definible exclusivamente con la cronología sino más bien por la suma de las condiciones físicas, funcionales, mentales y de salud de las personas analizadas. Hablamos de la edad fisiológica según el envejecimiento de órganos y funciones. De la edad psíquica o mental, según el grado de madurez, envejecimiento psicológico. Y existe otra edad, la subjetiva según el envejecimiento que experimenta la propia persona. Por tanto, la ancianidad es un concepto dinámico, pues hay que tener en cuenta que la edad biológica puede diferir marcadamente de la cronológica, y ambas de la subjetiva. (Olmos, 2009, p. 8) 
Esta nueva concepción, sin duda, propende por superar el imaginario, bastante manejado por las ciencias económicas, que define la vejez solo en términos de edad. Al respecto, hablar de una concepción del AM, desde las ciencias económicas, no resulta sencillo, debido a que las dimensiones que se manejan desde la economía privilegian el criterio de la edad como orientador principal, lo cual está acompañado por el proceso de envejecimiento fisiológico y de productividad, determinado por las actitudes y las conductas que se tienen con respecto a la edad (Comisión Económica para América Latina y el Caribe [Cepal], 2011).

La primera asociación al concepto de AM se configura por la definición cronológica, que es un criterio que difiere por las diferentes legislaciones y culturas, por lo que es difícil de determinar de manera específica. Sin embargo, la mayoría de los países, principalmente los países en vías de desarrollo, coinciden en que esta etapa de la vida inicia a los 60 años, criterio que marca, en algunas legislaciones de América Latina, la edad de jubilación. ${ }^{1}$ Esta concepción desde la edad cronológica se relaciona con la pérdida de productividad, debido a la disminución que las personas sufren de las capacidades funcionales que les permiten mantenerse autónomas, independientes y con la capacidad de producir para ellas y otras.

Otra concepción hace referencia a la fisiología; en este caso, la vejez, además de estar enmarcada en la edad cronológica, se determina por la pérdida de capacidad física (a nivel muscular y de fuerza) que tienen las personas, lo que las lleva a un deterioro "natural" físico o mental-de forma separada o en forma conjunta-, que les impide tener una vida social independiente (Centro Latinoamericano y Caribeño de Demografía [Celade], 2001).

$1 \quad$ En Colombia, al igual que en Venezuela, las personas se jubilan más jóvenes con una pensión completa: 55 años, para las mujeres, y 60 años, para los hombres. En el resto del mundo nos igualan las Islas Fiji, Costa de Marfil, Ruanda y la mayoría de los países de Medio Oriente y norte de África, entre otros. Aunque se tiene previsto que a partir del 1 de enero de 2014 la edad de jubilación para mujeres será de 57 años y para hombres, de 62 años. El único país que está por debajo de Colombia es Turquía, donde las mujeres dejan de trabajar a los 44 años y los hombres a los 47. Colombia está por debajo de países como Argentina, Brasil y Chile, donde los hombres deben cumplir 65 años para pensionarse, y en países como Estados Unidos, Australia y el Reino Unido se requiere tener más de 67, tanto para hombres como para mujeres. 
Finalmente, los dos anteriores aspectos conducen a una relación directa e intrínseca con la productividad; el término AM se refiere, así, a una etapa donde los procesos de producción, las tendencias de consumo y la generación de tributación disminuyen, con motivo del retiro de la "actividad laboral" que es reemplazada por actividades de diversión, disfrute y placer (Cepal, 2011).

Sin embargo, el cese de la actividad laboral no necesariamente representa cambios positivos, es común encontrar AM que se ven obligados a afrontar la desprotección y la marginalización. Un ejemplo bastante ilustrador de esta situación es el caso de los ancianos japoneses, para quienes la cárcel se ha vuelto en el último refugio, al punto de que

roban para ir a la cárcel y huir de una sociedad individualista que los ignora. La pequeña delincuencia protagonizada por la tercera edad es un fenómeno en alza en Japón, el último informe anual sobre delincuencia de la policía japonesa ha sembrado la inquietud. Las estadísticas muestran que uno de cada cuatro japoneses detenidos por robar en el 2010 era mayor de 65 años. En 1986, cuando se empezó a confeccionar este tipo de estadísticas, solo uno de cada veinte japoneses detenido por hurto era mayor de 65. (La Vanguardia, 2013)

Esta situación demuestra la ruptura de la tradición ancestral nipona de reunir bajo un mismo techo a tres generaciones de la misma familia. En la cárcel, los AM tienen techo, comida caliente y compañía; cuentan con espacios especiales y tienen que trabajar 6 horas diarias, 2 horas menos que los demás internos. Este tratamiento diferencial y especial, sin embargo, no es la norma en los EPC de todos los países; por el contrario, la privación de la libertad representa para muchos AM un evento desafortunado y hostil. Al respecto, se encuentra la siguiente declaración, en relación con la experiencia en España:

La ancianidad se acompaña de un mayor número de padecimientos que muchas veces coexisten a la vez. Existe con alta frecuencia procesos degenerativos, como deterioro cognitivo, enfermedades cardiovascu- 
lares, limitaciones del aparato locomotor, cáncer. Sin olvidar que una buena parte de nuestros pacientes por su historial de abusos de sustancias tóxicas agravan su situación y presentan todavía más deterioro que la población no reclusa. Estos procesos degenerativos establecidos de forma crónica y perenne, junto con la presencia de caídas, accidentes o alteraciones de los sentidos llevan a un final común que es la Invalidez y la Dependencia. Y una marcada pérdida de funcionalidad. (Ministerio del Interior del Gobierno de España, Secretaría General de Instituciones Penitenciarias, s. f.)

Es común, entonces, encontrar una relación directa entre la adultez mayor y la enfermedad, el deterioro físico y la improductividad, entre otros aspectos, lo cual posiblemente responde a entender la vejez como una etapa específica y no como un proceso. Arango y Ruiz (2001) afirman, en relación con el tema del envejecimiento y la vejez, que se refieren al "conjunto de modificaciones morfológicas y fisiológicas que aparecen desde el mismo momento del nacimiento, se incrementa con el paso del tiempo e involucra a todos los seres vivos. Es un proceso biológico, social y psicológico, como resultado de la interacción de la herencia, el ambiente y la conducta y va delineando la última etapa de la vida: la vejez" (Arango \& Ruiz, 2001). Una población se considera envejecida en la medida en que el $7 \%$ está conformado por personas de 60 años o más. ${ }^{2}$ En el caso de América Latina se cuenta con el siguiente panorama (tabla 2).

2 El índice de envejecimiento es un indicador del proceso que muestra la relación existente entre la cantidad de personas mayores de 60 años y la de niños y jóvenes menores de 15 años; cuando está por debajo de 100, existen menos personas de 60 años que menores de 15 años, y se encuentra por encima de 100 cuando el número de personas mayores de 60 años supera al de niños y adolescentes. 
Tabla 2. Índice de envejecimiento de la población 1950-2050 en América Latina

\begin{tabular}{|c|c|c|c|c|c|}
\hline País/Country & 1950 & 1975 & 2000 & 2025 & 2050 \\
\hline Argentina & 23,1 & 39,0 & 48,1 & 75,5 & 135,6 \\
\hline Bolivia & 13,6 & 12,9 & 16,1 & 31,0 & 82,1 \\
\hline Brasil/Brazil & 11,7 & 15,0 & 27,3 & 73,8 & 146,6 \\
\hline Chile & 18,7 & 21,4 & 35,8 & 82,2 & 131,9 \\
\hline Colombia & 11,7 & 12,9 & 20,9 & 55,2 & 116,1 \\
\hline Costa Rica & 19,8 & 16,7 & 23,8 & 74,0 & 155,9 \\
\hline Cuba & 20,4 & 26,5 & 64,3 & 156,5 & 221,1 \\
\hline Ecuador & 20,6 & 14,0 & 20,5 & 53,1 & 124,1 \\
\hline El Salvador & 11,1 & 10,4 & 20,2 & 41,0 & 106,9 \\
\hline Guatemala & 9,7 & 9,7 & 12,1 & 21,5 & 65,6 \\
\hline Haití & 22,3 & 17,1 & 14,1 & 26,9 & 74,3 \\
\hline Honduras & 8,7 & 8,7 & 12,4 & 30,4 & 85,6 \\
\hline México & 16,9 & 12,2 & 20,9 & 58,2 & 143,4 \\
\hline Nicaragua & 9,3 & 8,3 & 10,7 & 25,6 & 79,7 \\
\hline Panamá & 16,1 & 15,2 & 24,9 & 58,0 & 118,4 \\
\hline Paraguay & 22,9 & 16,5 & 13,5 & 30,6 & 76,0 \\
\hline Perú & 13,7 & 12,9 & 20,5 & 51,5 & 119,6 \\
\hline $\begin{array}{l}\text { República Dominicana/ } \\
\text { Dominican Republic }\end{array}$ & 11,6 & 10,4 & 19,8 & 52,5 & 116,9 \\
\hline Uruguay & 42,3 & 51,0 & 69,2 & 93,4 & 144,5 \\
\hline Venezuela & 7,9 & 11,4 & 19,4 & 54,6 & 120,3 \\
\hline
\end{tabular}

Fuente: Cepal-Celade.

De acuerdo con esto, Colombia se encuentra, al igual que el resto de países de América Latina, en un acelerado proceso de envejecimiento; el aumento de los Am frente a las tasas de fecundidad ubica al país en un proceso de envejecimiento moderado, ${ }^{3}$ frente a otros países de Latinoamérica.

3 El envejecimiento se ha clasificado demográficamente en cinco grandes categorías (Celade, 2010): 
Ante esto, la concepción de AM cada día cobrará mayor importancia en la media en que el peso relativo del total de la población siga en aumento.

Tabla 3. Índice de envejecimiento vs. tasa global de fecundidad en América Latina

\begin{tabular}{|c|c|c|c|}
\hline Etapas & Países & $\begin{array}{c}\text { Índice de } \\
\text { envejecimiento }\end{array}$ & $\begin{array}{c}\text { Tasa global de } \\
\text { fecundidad }\end{array}$ \\
\hline \multirow{18}{*}{$\begin{array}{l}\text { Envejecimiento } \\
\text { incipiente }\end{array}$} & Belice & 16,7 & 2,8 \\
\hline & Bolivia (Est. Plur. de) & 20,1 & 3,3 \\
\hline & Guatemala & 15,1 & 3,9 \\
\hline & Guayana Francesa & 19,5 & 3,1 \\
\hline & Haití & 18,0 & 3,4 \\
\hline & Honduras & 16,8 & 3,1 \\
\hline & Nicaragua & 18,1 & 2,7 \\
\hline & Paraguay & 22,8 & 3,0 \\
\hline & Colombia & 29,8 & 2,2 \\
\hline & Ecuador & 30,9 & 2,5 \\
\hline & El Salvador & 32,2 & 2,3 \\
\hline & Guyana & 32,4 & 2,3 \\
\hline & Jamaica & 37,0 & 2,3 \\
\hline & Panamá & 33,6 & 2,5 \\
\hline & Perú & 29,1 & 2,5 \\
\hline & República Dominicana & 27,6 & 2,6 \\
\hline & Suriname & 32,7 & 2,4 \\
\hline & Venezuela (República Bolivariana de) & 29,3 & 2,5 \\
\hline
\end{tabular}

a) Envejecimiento incipiente: cuenta con una tasa de fecundidad de más de 3,3 hijos, frente a 23 AM por cada 100 menores.

b) Envejecimiento moderado: cuenta con una tasa de fecundidad de entre 2,7 y 2,3 hijos, frente a AM que representan entre el $27,6 \%$ y el $37 \%$ por cada 100 menores.

c) Envejecimiento moderado avanzando: cuenta con una tasa de fecundidad de entre 2,1 y 1,8 hijos, frente a AM que representan entre el $33 \%$ y el $42 \%$ por cada 100 menores.

d) Envejecimiento avanzando: cuenta con una tasa de fecundidad entre 1,8 y 2,1 hijos, frente a AM que representan entre el $51 \%$ y el $82 \%$ por cada 100 menores.

e) Envejecimiento muy avanzado: cuenta con una tasa de fecundidad entre 1,5 y 1,9 hijos, frente a AM que representan entre el $91 \%$ y el $100 \%$ por cada 100 menores. 


\begin{tabular}{|c|c|c|c|}
\hline Etapas & Países & $\begin{array}{c}\text { Índice de } \\
\text { envejecimiento }\end{array}$ & $\begin{array}{c}\text { Tasa global de } \\
\text { fecundidad }\end{array}$ \\
\hline \multirow{5}{*}{$\begin{array}{l}\text { Envejecimiento } \\
\text { moderadamen- } \\
\text { te avanzado }\end{array}$} & Bahamas & 41,3 & 2,0 \\
\hline & Brasil & 39,8 & 1,8 \\
\hline & Costa Rica & 37,3 & 2,0 \\
\hline & México & 33,9 & 2,1 \\
\hline & Santa Lucía & 38,6 & 2,0 \\
\hline \multirow{6}{*}{$\begin{array}{l}\text { Envejecimiento } \\
\text { avanzado }\end{array}$} & Antillas Neerlandesas & 75,6 & 1,9 \\
\hline & Argentina & 58,1 & 2,3 \\
\hline & Chile & 58,1 & 1,9 \\
\hline & Guadalupe & 62,1 & 2,1 \\
\hline & Trinidad y Tobago & 51,5 & 1,7 \\
\hline & Uruguay & 81,7 & 2,1 \\
\hline \multirow{4}{*}{$\begin{array}{l}\text { Envejecimiento } \\
\text { muy avanzado }\end{array}$} & Barbados & 90,0 & 1,6 \\
\hline & Cuba & 100,0 & 1,5 \\
\hline & Martinica & 97,5 & 1,9 \\
\hline & Puerto Rico & 97,8 & 1,8 \\
\hline
\end{tabular}

Fuente: Celade (2010).

En los EPC, aunque no se cuenta con los datos de la tasa global de fecundidad, lo que permitiría evidenciar la categoría de envejecimiento en la que se encuentra su población, el aumento de las penas hace prever que, independientemente de la situación jurídica definida, los internos vienen envejeciendo y la población de AMPL continúa con una tendencia al alza, y, literalmente, esta población tiene como única esperanza concluir su vida encarcelada (figura 3). Curiosamente, aunque no existe cadena perpetua en Colombia, el aumento de las penas, junto con el incremento de la esperanza de vida, la longevidad y los índices de envejecimiento permiten suponer que implícitamente esta pena es una realidad en el país. 
Figura 3a. Número de adultos mayores privados de la libertad 2009-2013 (comportamiento de edad y sexo)

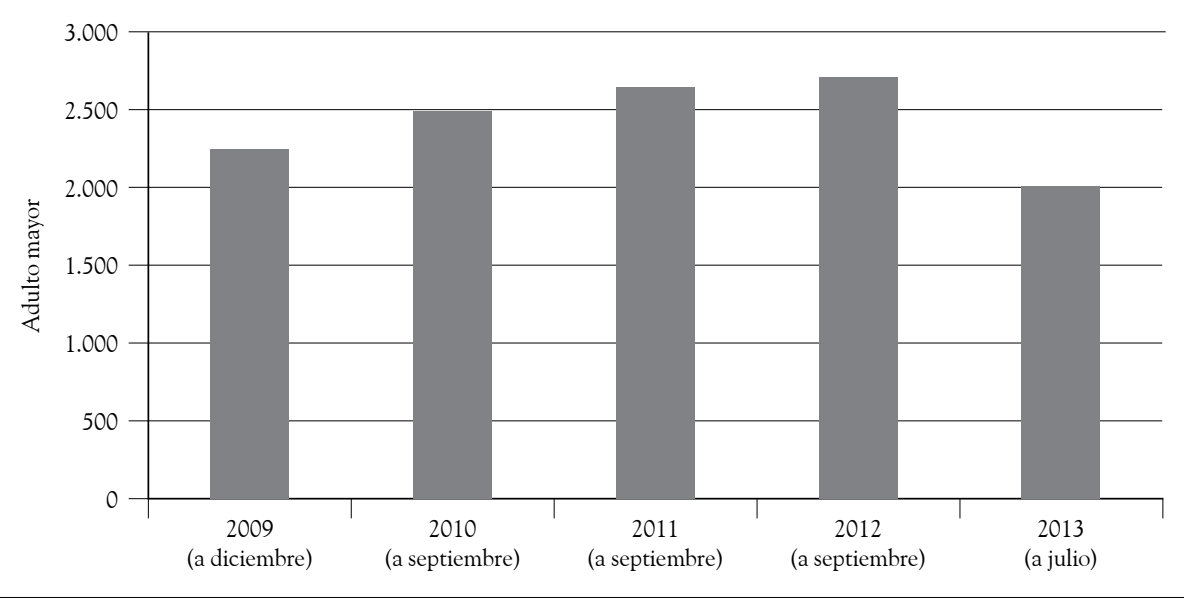

Figura 3b. Adultos mayores privados de la libertad

(distribución por de edad y sexo)

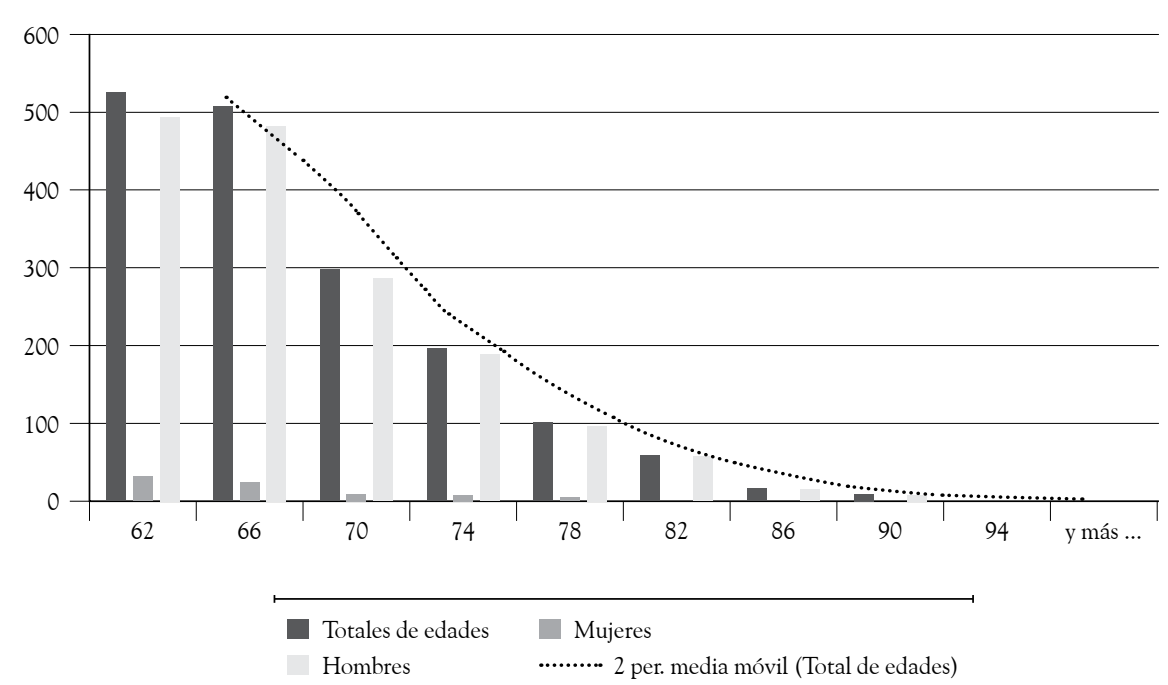

Fuente: plan de compras del Inpec para cada vigencia, y censo de condiciones excepcionales, 31 de julio de 2013 del Sisipec Web. Cálculos de los autores. 


\section{El concepto del adulto mayor desde diversas disciplinas}

En el presente apartado se abordan las diferentes concepciones sobre el AM, acogidas y desarrolladas desde las ciencias jurídicas, la psicología, la economía y la sociología, y contrastadas con la información empírica. Hacer referencia a las temáticas relacionadas con el AM en prisión se convierte en un reto que invita al análisis de cada uno de los términos que se utilicen con el fin de mostrar realidades encontradas en esta población.

Lo anterior, permite entender por qué se elige el término "concepción" como el "conjunto de ideas que se tienen sobre alguna cosa" (Real Academia Española [RAE], 2013); no como parte del entramado de fríos conceptos que se exponen de manera sistemática, secuencial y cronológica con el fin de lograr ilustrar algo, sino como el conjunto de ideas acompañadas de preguntas que son el vehículo que permite aproximarse a la manera como se llega a concebir la imagen que se tiene de algo.

\section{Perspectiva jurídica del adulto mayor}

Tanto la CN, en su artículo 46, como la ley hacen referencia al concepto de adulto mayor; la primera lo señala como persona de la tercera edad, mientras que la ley lo define como aquella persona que cuenta con sesenta (60) años de edad o más. Este último criterio se enfatiza en la Ley 1251 de 2008, artículo 3, normatividad que, además, incluye las definiciones de vejez: "Ciclo vital de la persona con ciertas características propias que se producen por el paso del tiempo en el individuo" (Congreso de Colombia, 2008), y de envejecimiento: "Conjunto de modificaciones que el paso del tiempo ocasiona de forma irreversible en los seres vivos" (Congreso de Colombia, 2008).

De manera semejante, el anterior criterio es reiterado por la Ley 1276 de 2009, artículo 7, literal b, cuando señala: "Adulto Mayor es aquella persona que cuenta con sesenta (60) años de edad o más. A criterio de los especialistas de los centros vida, una persona podrá ser clasificada dentro de este rango, siendo menor de 60 años y mayor de 55, cuando sus condi- 
ciones de desgaste físico, vital y psicológico así lo determinen" (Congreso de Colombia, 2009).

Pareciera, entonces, que desde el punto de vista legal, el concepto de adulto mayor principalmente está atado al de la edad, que es considerada para la jubilación y, a través del requisito pensional, se pretende armonizar y generalizar su definición, puesto que apenas la Ley 1276 muy tímidamente se atreve a incluir otras características relativas a lo físico, lo vital y lo psicológico.

Lo anterior, nos conduce a asumir o adentrarnos en el campo de la seguridad social, por ser la línea conductora y reguladora del adulto mayor en Colombia. A partir de un recuento histórico en cuanto a asistencia y seguridad social del AM, Arenas-Monsalve (2007) describe cinco etapas en la historia de la seguridad social en Colombia: desde el nacimiento de la República hasta 1945, un periodo de organización desde 1945 hasta 1967, un periodo de expansión desde 1967 hasta 1977, un periodo de cambios y crisis desde 1977 hasta 1990 y un periodo de reformas estructurales a partir de 1990.

En la primera etapa se percibe una desatención por parte del Estado, por lo que se le delegaba a la caridad la obligación frente al particular. Posteriormente, gracias a Rafael Uribe Uribe, se implementa, aunque solo hasta 1936, el programa Socialismo de Estado, que buscaba vincular al Estado con el tema de la seguridad social. Con la Ley 90 de 1946 se implementa un modelo de seguridad social que vela por la protección de los trabajadores y, en adelante, se formula otra normatividad, como el Decreto 1824 de 1965, la Ley 4 de 1976 o la Ley 1650 de 1977, que propendió por definir los aspectos concernientes a la seguridad social y velar por su cumplimiento (Ciprián-Carvajal, 2011).

Otro aspecto importante es que, previo al inicio de la década de los setenta, se crea, por medio de la Ley 75 de 1968, el Instituto Colombiano de Bienestar Familiar, encargado de prestar asistencia por enfermedad, invalidez o calamidad a los que se encontraran afiliados. Posteriormente, se expide la Ley 29 de 1975, a través de la cual se crea la protección a la ancianidad, y surge el Fondo Nacional de la Ancianidad Desprotegida para favorecer a las personas que tengan más de 60 años y que se encuentren en estado de indefensión, pobreza y quebrantos de salud (Congreso de Colombia, 1975). 
En la década de los ochenta surge la Ley 48 de 1986, "por la cual se autoriza la emisión de una estampilla pro-construcción, dotación y funcionamiento de los centros de bienestar del anciano, se establece su destinación y se dictan otras disposiciones" (Congreso de Colombia, 1986); se invoca esta ley como antecedente de una intención más para la protección del AM en ese momento histórico.

En la década de los noventa, se señala el Día de la Tercera Edad y el Pensionado, en la Ley 271 de 1996, y se hace alusión al principio de dignidad, sin que se haya desarrollado una política pública seria al respecto. Con la Constitución del 91 se expidió la Ley 100 de 1993, que, como se sabe, constituyó el hito más importante en la materia, fue el objeto de algunas reformas y, en la actualidad, se tiene la perspectiva de modificarla.

El hecho de que legalmente no se fortalezca la concepción del AM a nivel nacional conduce a la poca importancia que se le sigue dando al tema y a que no exista claridad sobre quiénes son, tanto desde el punto de vista del Estado a través de sus diferentes servidores, los que tendrían que dispensar su cuidado y protección, como desde la arista de quiénes lo necesitan; al punto de que dicho vacío, contrario a lo que pasa con los menores, quienes cuentan con todo un código al respecto, ha generado una reacción puntual sobre el tema, como es el caso del Distrito Capital, que aventaja en dichas políticas a lo nacional.

En cuanto a los hallazgos de campo, es común encontrar entre las opiniones de los participantes que el concepto de AM se vincula inmediatamente con la edad, lo que guarda coherencia con lo planteado en la legislación nacional; de esta manera, se afirma reiterativamente que "un adulto mayor es una persona que está por encima de los 60 años" (grupo focal, Comeb, julio de 2013, Bogotá). En cuanto a la seguridad social, se encontró que aunque son pocos, algunos de los participantes se encuentran cubiertos por el régimen pensional, aunque la prisión se vuelva una limitante para el goce efectivo de este derecho. "Yo soy pensionado y aquí me atiende mi EPS, pero cuando mi familia me pide una cita, no me llevan, me la cancelan, y luego piden otra cita, y me hacen perder las citas... me han hecho perder 3 citas donde los especialistas, donde los cirujanos [...]" (grupo focal, EPMSC, julio de 2013, Medellín). 


\section{La vejez desde las teorías psicológicas}

Antes de profundizar en las variables psicológicas específicas que se tuvieron en cuenta para el estudio, es necesario retomar algunos aportes que ayudan en la comprensión del concepto vejez. Al tener en cuenta que el trascurrir de la vida implica el "uso" de las funciones psicofisiológicas de manera continuada, se entiende que en el desarrollo del proceso de envejecimiento se observen cambios en el cuerpo que son producto de las modificaciones en su química: baja de la masa muscular, además de la "disminución para responder de manera funcional a las variaciones del ambiente, incremento en la vulnerabilidad a enfermedades y mortalidad de las personas", entre otros (Cristófalo, 1991); luego, el envejecimiento se asocia con el desgaste, la disminución, la mengua. En una línea muy similar, la OMs (citado en Gión et al., 2011) se ha centrado en diferenciar los conceptos de envejecimiento como proceso y proceso de envejecimiento, así como de la promoción de la idea de envejecimiento activo, descritos así:

Tabla 4. El envejecimiento según la Organización Mundial de la Salud

\begin{tabular}{|l|l|l|}
\hline \multicolumn{1}{|c|}{ Envejecimiento como proceso } & Proceso de envejecimiento & \multicolumn{1}{c|}{ Envejecimiento activo } \\
\hline $\begin{array}{l}\text { También llamado envejecimien- } \\
\text { to normal, en el que se hace } \\
\text { referencia a los cambios bioló- }\end{array}$ & $\begin{array}{l}\text { Este concepto tiene rela- } \\
\text { ción con factores ambien- } \\
\text { tales, de estilo de vida y y } \\
\text { gicos esperables relacionados } \\
\text { enfermedades que pueden } \\
\text { con la edad, sin afectación por } \\
\text { causo de hacerse mayor sin } \\
\text { envejecer mediante el de- } \\
\text { estar vinculadas con el en- } \\
\text { conficiones del entorno. }\end{array}$ & $\begin{array}{l}\text { sarollo continuado de ac- } \\
\text { tividades físicas, sociales } \\
\text { vejecimiento, pero no se } \\
\text { y espirituales a lo largo de } \\
\text { toda la vida". }\end{array}$ \\
\hline
\end{tabular}

Fuente: OMS (citado en Gión et al., 2011).

Es notorio que existe una preocupación por diferenciar las consecuencias propias del envejecimiento de las que son producto de factores que si bien tienen relación con este, aparecen como causas externas necesariamente vinculadas a estilos de vida y condiciones del entorno que pueden ser o no elección del individuo. Finalmente, aparece una estrategia que busca hacer frente al proceso de envejecimiento, que consiste en preparase para el envejecimiento normal durante toda la vida. 
Además de los anteriores, se encuentran los conceptos de envejecimiento primario, que implica cambios que inevitablemente se presentarán con la edad, y envejecimiento secundario, referente a los cambios causados por afecciones que no son resultado de la edad (Moreno, 2004). Estos se han adoptado para intentar explicar el envejecimiento únicamente desde el aspecto físico, y están enmarcados en la teoría de la preprogramación genética que afirma la reproducción de las células solo hasta una cierta edad, y las teorías del desgaste según las cuales las funciones mecánicas del cuerpo dejan de trabajar de manera idónea (Berger \& Thompson, 2009). Las ideas expuestas hasta el momento muestran unos puntos de encuentro entre las diferentes posturas:

1. Se observa el envejecimiento como parte de un proceso que se da a lo largo de la vida y no como un episodio estático o apartado de esta.

2. Se entiende que existe un acuerdo entre algunas características deseables relacionadas con la preparación que debe hacer cada individuo para enfrentar la vejez.

3. Presencia del deterioro que da lugar a la exigencia de realizar ajustes para lograr la adaptación funcional en diversas esferas.

Estos postulados se convierten en un marco de referencia inicial que sirve para sentar las bases con respecto del término AM; por tanto, no pretenden convertirse en definiciones estandarizadas ni son aplicables a toda esta población. Como referencia inicial, admiten vinculaciones de diversas categorías de análisis con el ánimo de lograr el mayor acercamiento posible a lo que sería la definición desde el punto de vista que integra posturas psicológicas y percepciones de los protagonistas de esta investigación. Ese ánimo conlleva la inclusión de percepciones, ideas, pensamientos o juicios de internos que participaron en grupos focales, desarrollados en EPC del país. El resultado que se obtuvo fue un concepto de AM desde lo psicológico que se interpreta a partir de algunas categorías previamente mencionadas y otras que emergen producto de la participación e interacción con los que 
se consideran principales actores de este trabajo investigativo, los AMPL. En la tabla 5 se puede visualizar la matriz de codificación utilizada.

Tabla 5. Dimensiones del concepto adulto mayor

\begin{tabular}{|c|c|c|c|c|c|}
\hline 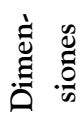 & Pensamientos & $\begin{array}{l}\text { Indicadores } \\
\text { psicológicos } \\
\text { de vejez }\end{array}$ & $\begin{array}{l}\text { Envejecimiento } \\
\text { como proceso }\end{array}$ & $\begin{array}{c}\text { Proceso de } \\
\text { envejecimiento }\end{array}$ & $\begin{array}{c}\text { Trato } \\
\text { diferencial }\end{array}$ \\
\hline \multirow{3}{*}{ 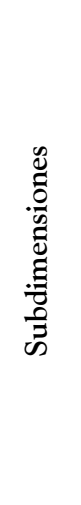 } & $\begin{array}{l}\text { Pensamiento } \\
\text { acerca de la } \\
\text { edad en tiempo. }\end{array}$ & $\begin{array}{l}\text { Capacidad/inca- } \\
\text { pacidad en acti- } \\
\text { vidades. }\end{array}$ & $\begin{array}{l}\text { Cambios } \\
\text { esperables. }\end{array}$ & $\begin{array}{l}\text { Condiciones } \\
\text { ambientales. }\end{array}$ & $\begin{array}{l}\text { Buen } \\
\text { trato. }\end{array}$ \\
\hline & $\begin{array}{l}\text { Pensamientos } \\
\text { acerca de la } \\
\text { edad como } \\
\text { estado mental. }\end{array}$ & Dependencia. & $\begin{array}{l}\text { Reconoci- } \\
\text { miento del } \\
\text { estado o de la } \\
\text { edad. }\end{array}$ & & $\begin{array}{l}\text { Atención } \\
\text { médica. }\end{array}$ \\
\hline & $\begin{array}{l}\text { Otras carac- } \\
\text { terísticas para } \\
\text { describir al AM. }\end{array}$ & Involución. & & & $\begin{array}{l}\text { Exclu- } \\
\text { sión. }\end{array}$ \\
\hline
\end{tabular}

Fuente: elaboración propia.

\section{Pensamientos}

El pensamiento como producto cognitivo no puede ser medido directamente, sino mediante la observación de su materialización en acciones, y tiene una influencia determinante en las representaciones del individuo acerca de lo que conoce, por cuanto su fin se constituye en encontrar soluciones a los problemas o mantenerse en una constante búsqueda de estas. En coherencia con esta definición, existe una estructura propuesta por Ericsson y Hastie (1994) que permite ubicar como principales funciones del pensamiento las de categorizar, razonar, decidir, solucionar problemas e inventar. A partir de esta propuesta, se encuentra que los AM participantes establecen categorías para el concepto de AM que agrupadas se refieren a la edad, un estado mental y otras características. 


\section{Pensamientos acerca de la edad en tiempo}

Cuando se habla del paso del tiempo, es obligatorio tocar el tema de la edad; al respecto, la población ubica la adultez mayor a partir de los 60 años de edad, lo que guarda coherencia con lo establecido en el ordenamiento legal (Congreso de Colombia, 2008). Otra idea relacionada con la edad es la tendencia a realizar una comparación retrospectiva que refleja el sentimiento de estar más jóvenes, entre los 25 a los 30 años, etapa de la vida que algunos autores consideran como la más productiva y, que al parecer, los participantes perciben de la misma manera: "Pero nosotros podemos ser más jóvenes mentalmente que un muchacho de 25" (grupo focal, EPMSC, julio de 2013, Medellín), "el cuerpo, que uno no tenga ningún, como se llama, dolor que lo domine a uno, es decir que uno se sienta como de 30 años. Yo me siento así, como de 30 años de juventud" (grupo focal, Comeb, julio de 2013, Bogotá).

\section{Pensamientos acerca de la edad como estado mental}

Para establecer el significado de la expresión estado mental, se toma como referencia a Lubrano (citado en Mora, et al., 2004), en cuanto a que en términos generales el estado mental denota el funcionamiento de áreas como la conciencia, el estado de ánimo, el afecto, el pensamiento, la conducta, entre otros; es decir, permite describir si estas funciones se están desarrollando de forma correcta o incorrecta.

Análoga a esta definición, está la referencia que hacen los participantes al término estado mental para representar positivamente cómo se perciben con respecto de su edad. Tal vez por eso, para ellos la vejez no está asociada al paso del tiempo o al número de años que tienen, sino a un conjunto de pensamientos que la constituyen, como algo que se lleva en la mente y, por lo tanto, se puede cambiar. En ese sentido, han convertido la edad en una experiencia subjetiva que no se circunscribe a medidas de tiempo por cuanto no es considerada como la principal característica que los describa: "Es un estado mental, el que se cree viejo, es viejo" (grupo focal, EPMSC ERE, julio de 2013, Cali), "pues yo creo que la edad la tiene uno en la mente. 
Uno es joven lo que se sienta de joven. Si uno a los 90 años se siente joven, es joven" (grupo focal, Comeb, julio de 2013, Bogotá). En consecuencia, el estado mental que se refleja en los pensamientos, las actitudes, las acciones o las percepciones se puede enmarcar dentro de lo positivo o lo negativo, y de esta forma influir y reflejar cómo se asume la vejez frente a la vida.

\section{Otras características para describir al adulto mayor}

La utilización de conceptos permite realizar asociaciones por características que dan como resultado nuevos términos con los que podemos describir objetos o personas. En este sentido, Murphy (citado en Limón, 2005), los define como un pegamento que tiene como función conectar experiencias del pasado con las interacciones que en la actualidad se están teniendo con el mundo. Esta capacidad permite a los individuos designar particularidades para hablar de algo o de alguien sin tener que mencionarlo y, para el caso de los entrevistados, específicamente, han conseguido conceptualizar al AM mediante la asignación de atributos como la sabiduría, la conciencia de los actos, la responsabilidad, de los cuales resaltan que son adquiridos por el paso del tiempo y la suma de experiencias. Un análisis tentativo puede indicar que estos atributos solo llegan a darse por la conjugación de la edad, y asumir un estado mental positivo que los posiciona sobre las personas más jóvenes: "Es decir, el AM es el que tiene conciencia de sus actos en toda su palabra" (grupo focal, Comeb Bogotá, julio 2013).

\section{Indicadores psicológicos de vejez}

Los participantes en los grupos focales no se limitaron a la simple construcción de un significado, sino que hicieron referencia a una serie de aptitudes o recursos con los que cuentan para el desarrollo de actividades. Estas acepciones se interpretan como indicadores de vejez que acompañan este concepto. En otras palabras, se constituyen en características atribuibles a esta etapa, ya no en términos de pensamiento, sino de acciones. 


\section{Capacidad/incapacidad en actividades}

El primer indicador planteado consiste en reconocer si, como AM, cuenta o no con los recursos personales para desempeñar una actividad. En términos expresados por los participantes, esto se relaciona con la palabra "capacidad". En este sentido, al percibirse con capacidades, se afirman en la idea de mantenerse al margen del envejecimiento. "Mire, acá hay capacidad laboral que no la tiene la juventud, aquí en este momento, nos la pasamos laborando, haciendo dibujos, manualidad, que una cosa que la otra" (grupo focal, EPMSC ERE Cúcuta, julio de 2013). No obstante, tienen presente que la capacidad se puede perder, y, si aún la conservan, puede ser debido al estado mental o la actitud, que se mencionaron anteriormente. Luego, este parámetro surge para identificarse positivamente.

En oposición, surgieron afirmaciones con las que se evaluaron negativamente, en las que se atribuía que la experiencia de envejecer era la ausencia total de capacidades, producto del paso de los años. "Ya uno tanta edad, iya qué! Ya no es capaz uno de nada” (grupo focal, Coiba Ibagué, junio de 2013). Aquí vale la pena detenerse un momento para analizar que si este es un parámetro bajo el cual se ha de medir la vejez desde una óptica negativa, es casi imposible que lleguen a considerarse viejos, en cuanto el deterioro que implicaría la incapacidad de hacer cualquier cosa; aunque puede aparecer, no es frecuente para esta población.

Esta polarización, igual que la edad asociada al estado mental y no al tiempo, prevé una situación gana-gana en el AM, porque lo ubica siempre cerca de cumplir los indicadores positivos y muy lejano de los negativos, toda vez que las circunstancias de incapacidad total son poco probables.

\section{Dependencia}

Es evidente que el cúmulo de tiempo tiene consecuencias contrarias a las deseadas, una de estas hace alusión a la dependencia, la cual fue descrita en situaciones en las que se requiere de otros para hacer cosas que regularmente los AM hacían solos. Esto se refleja en el malestar de tener que necesitar de 
alguien y, por ende, se puede entender como la pérdida de autonomía, si se considera que consiste en mantener la propia individualidad y la libertad personal, relacionadas con la autodeterminación (Ortiz \& Castro, 2009). "Empecé a ser vieja, por ejemplo, cuando me tocó valerme por medio de mi hija porque yo ya no" (grupo focal, Complejo Carcelario y Penitenciario de Medellín Pedregal [Coped], julio de 2013).

\section{Involución}

El término hace referencia a la posibilidad de volver a estados anteriores, en cuanto a tener necesidades específicas, lo que es producto del avanzado deterioro de las funciones físicas y cognitivas, y su impacto en lo social. En este sentido, el hecho de tener que depender del cuidado de los demás en actividades básicas es equiparable a estar viejo, y ese envejecimiento conduce a que los AM se perciban en estados de indefensión en los que necesitan de mayor atención, a tal punto que, paradójicamente, al percibirse como viejos, dicen que necesitan ser atendidos como niños. "Porque está como un niño ya que requiere de muchos tratamientos, de mucha compasión, creo que será eso" (grupo focal, EPMSC Bucaramanga, julio de 2013). Puede ser que la referencia al niño encierre un significado despectivo respecto de la forma en que les gustaría ser atendidos en sus necesidades especiales.

Hasta el momento, se han mostrado las consideraciones que influyen en los participantes en cuanto al concepto de AM. En primera instancia, se contemplaron los pensamientos referentes a la edad en términos de tiempo; la edad y la vejez como estado mental, y otras características emergentes que se atribuyen al AM como indicadoras de esta etapa, enmarcadas en la capacidad y la dependencia, como la pérdida de autonomía y la involución.

\section{Envejecimiento como proceso}

La OMS (citado en Gión et al., 2011) contempla un envejecimiento normal con cambios a nivel biológico asociados a la edad, que excluye la influencia 
de factores patológicos o ambientales; bajo esta perspectiva, se encontraron descripciones de algunos cambios significativos y que conscientemente son reconocidos por los participantes como parte del proceso (figura 5).

\section{Cambios esperables}

La tabla 6 hace referencia a los cambios físicos y biológicos manifestados en "enfermedades" y "dolencias" que se describieron en cuanto al concepto de AM.

Tabla 6. Cambios físicos y biológicos manifestados

por los adultos mayores privados de libertad

\begin{tabular}{|l|l|}
\hline Condición biológica & \multicolumn{1}{c|}{ Cita } \\
\hline Aspecto físico & $\begin{array}{l}\text { "Se le van notando las arrugas a uno, la pata de gallina, icómo que } \\
\text { no? Uno no puede decir: no, es que no estoy". }\end{array}$ \\
\hline Visión & $\begin{array}{l}\text { "La visibilidad se va perdiendo". } \\
\text { "La vista, yo entre aquí sin gafas y aquí me dieron estas gafas". }\end{array}$ \\
\hline Condición motora & $\begin{array}{l}\text { "Unos pasamanos porque entonces ya empiezo a perder el equilibrio, } \\
\text { "Que disminuimos nuestro caminar". }\end{array}$ \\
\hline $\begin{array}{l}\text { Enfermedades } \\
\text { gastrointestinales }\end{array}$ & $\begin{array}{l}\text { "La mayoría, a esta edad entramos casi todos enfermos, yo por lo } \\
\text { menos tengo gastritis crónica, tengo úlceras, tengo hernias, tengo } \\
\text { de todo eso". }\end{array}$ \\
\hline $\begin{array}{l}\text { Enfermedades } \\
\text { crónicas }\end{array}$ & $\begin{array}{l}\text { "La mayoría tenemos enfermedades crónicas, por ejemplo yo soy } \\
\text { hipertenso, hay diabéticos, a veces aquí a uno le dan tratamiento, } \\
\text { no es que sea malo del todo. También tengo problemas cardiacos". }\end{array}$ \\
\hline
\end{tabular}

Fuente: elaboración propia.

\section{Reconocimiento del estado o de la edad}

La capacidad del ser humano de estar consciente de las acciones, los sentimientos, las emociones, el dolor, entre otros, le permite comprender la experiencia en relación consigo mismo y con el entorno. La autoaceptación 
es uno de los criterios del bienestar psicológico expuesto por Ryff (citado en Ortiz \& Castro, 2009), y tiene relación con experimentar una actitud positiva hacia sí mismo y hacia la vida pasada. Desde esta perspectiva, el proyectar o vivir la vejez requiere de un ejercicio consciente de aceptar los cambios o las nuevas formas en las que se represente la existencia.

A partir de la anterior afirmación, los grupos aceptaron la condición de AM como aquella que está enmarcada en una fase de la vida determinada por la edad, en la capacidad de asimilar lo que están viviendo (limitaciones) y los roles que se asumen: "que somos abuelos"; además, promueven la premisa del equilibrio que debe existir para enfrentar las situaciones de la mejor manera. "Es un estado mental, el que se cree viejo es viejo. Pero, perdón, pero sin perder tampoco la perspectiva, el tiempo en que estamos ni la situación que estamos, porque tampoco con sesenta, setenta u ochenta años tampoco me voy a creer que puedo hacer muchísimas cosas, se debe ser equilibrado dentro de un sistema, pero tampoco me voy a poner a hacer cosas que yo sé que no puedo hacer" (grupo focal, EPMSC ERE CALI, julio de 2013).

\section{Proceso de envejecimiento}

Entre los aportes que dan cuenta de las consecuencias no deseables del envejecimiento, se destacan los que son producto de factores que, si bien pueden tener relación con este, aparecen como causas externas necesariamente vinculadas a estilos de vida y condiciones del entorno que difícilmente para los AMPL son su elección (figura 6).

\section{Condiciones ambientales}

En el contexto de la prisión convergen una serie de factores ambientales que son adversos para el desarrollo psicosocial de quienes se encuentran allí. Como marco, se puede considerar lo expresado en la Sentencia T-153 de 1998: 
En efecto, tanto el derecho a la dignidad como el de no recibir tratos o penas crueles, inhumanos o degradantes se ven quebrantados por el hacinamiento y las malas condiciones de la estructura física y de servicios públicos que se encuentra en los centros de reclusión; los derechos a la vida y la integridad física son vulnerados o amenazados de manera inminente por el mismo hacinamiento, por la mixtura de todas las categorías de reclusos y por la carencia de los efectivos de guardia requeridos. (Corte Constitucional de Colombia, 1998)

Estos factores, junto con las enfermedades vinculadas al envejecimiento, las prácticas del estilo de vida en la cárcel y las necesidades de un trato diferencial, han sido claramente expresados por los AM y no les es difícil establecer la relación con el deterioro en la salud tanto mental como física. En la tabla 7 se muestra cómo se agruparon los aspectos institucionales que determinan las condiciones ambientales percibidas por los internos y las participaciones en las que relacionaron las condiciones con su estado de salud en referencia con el AM.

Tabla 7. Condiciones ambientales en el proceso de envejecimiento

\begin{tabular}{|l|l|}
\hline \multicolumn{1}{|c|}{ Condiciones } & \multicolumn{1}{c|}{ Cita } \\
\hline $\begin{array}{l}\text { Reglamento } \\
\text { régimen } \\
\text { interno }\end{array}$ & $\begin{array}{l}\text { "Tengo } 74 \text { años cumplidos y yo si me siento mal, ya no oigo y ya no veo y } \\
\text { aquí desafortunadamente en esta cárcel no tengo compasión de nadie, } \\
\text { aquí se monta uno por encima del otro a la hora de la comida, eso no } \\
\text { les interesa nada a ellos, entonces qué pasa aquí, no hay protección". }\end{array}$ \\
\hline Hacinamiento & $\begin{array}{l}\text { "Los dormitorios, estamos en un hacinamiento casi del 50\%, según } \\
\text { nosotros tenemos entendido que somos 52 y la capacidad de cada patio, } \\
\text { pero nosotros también entendemos que hay un hacinamiento, que hay } \\
\text { una superpoblación carcelaria que los del Inpec no tienen la culpa". }\end{array}$ \\
\hline Alimentación & $\begin{array}{l}\text { "La cuestión de la alimentación es precaria, yo soy hipertenso; no tengo } \\
\text { lo uno, los medicamentos, no nos los dan, eso era catapril y labrotadina, } \\
\text { elimento bajo de grasa, cero sodio y dieta blanca... y yo no sé qué, bajo } \\
\text { no estamos comiendo regularmente a una sola hora... entonces, eso } \\
\text { parece que altera mucho la cuestión digestiva y hasta la salud anímica } \\
\text { de nosotros". }\end{array}$ \\
\hline
\end{tabular}

Fuente: grupos focales en los EPC visitados. 
Los internos exponen que la experiencia de la adultez mayor en la cárcel se convierte en una carga que deben sobrellevar, experimentando la incomodidad, las amenazas de otros internos, la sensación de no contar con protección ni privilegios, como un lugar específico o dietas especialmente diseñadas. Observan la necesidad de ser ubicados como un grupo etario especial, en un espacio en el que los factores ambientales no sean los que determinen actividades tan básicas como la recepción del alimento o el descanso. "Que nos aíslen por allí en el ERON, pero que sea bien" (grupo focal, EPMSC ERE Cúcuta, julio de 2013).

\section{Trato diferencial}

El sometimiento a condiciones extremas, como las que exteriorizaron los internos AMPL en el apartado anterior, determina que las ideas de ser tratados de manera diferente están fijadas por las condiciones del contexto inmediato, más que por su condición de grupo etario que amerita una serie de acciones específicas enmarcadas, entre otras, en la Ley 1251 de 2008. "Debe de haber un privilegio para uno al llegar a cierta edad porque ya uno se exime de tantas cosas, entonces la mayoría no tiene ese sentimiento propio de pensar que uno tenga un privilegio" (EC de Bogotá, julio de 2013). En este sentido, no manifestaron la necesidad de ser tratados como un grupo con necesidades especiales como un derecho constituido, sino como un privilegio que se han ganado con la edad.

\section{Buen trato}

La petición de amabilidad como parte del respeto o la cortesía fue agrupada en la subdimensión de buen trato: "Yo sí pienso distinto a la señora, por ejemplo, si a mí usted o una de las niñas me dice como con rabia yo lo voy a tomar a mal, pero si me dice viejita linda mi cariño, yo se lo voy a aceptar" (grupo focal, Coped Mujeres Medellín, julio de 2013). Esto facilita las relaciones amables con los demás y, por norma social o etiqueta, son mínimas 
en la interacción cotidiana. En los aportes realizados por los AM, reclaman constantemente estos elementos como parte de la diferencia con la que piensan deben ser atendidos.

\section{Atención médica}

Para los integrantes de los grupos focales, esta es una necesidad prioritaria y lo que permite enmarcarla como trato diferencial es que, en las condiciones actuales, pareciera que no existen enfermedades asociadas al envejecimiento, sino a condiciones del ambiente, lo que implica que ya no pueden ser abordadas desde lo preventivo. Con respecto de esto, un interno comenta: "En la tercera edad que es indispensable que tengamos ese apoyo médico prioritario... para poder salir urgentemente al médico, es que uno se esté muriendo o herido" (grupo focal, EC de Bogotá, julio de 2013).

\section{Exclusión}

Existen percepciones de los internos relacionadas con el rechazo de otros o con la sensación de no ocupar el lugar que en determinado momento de su vida ocuparon. Las verbalizaciones muestran elementos con los que ellos han configurado un componente de exclusión al sentir el trato de los internos más jóvenes. Este se da desde la utilización de términos peyorativos para dirigirse a ellos: "Por qué a nosotros los abuelitos nos miran como un agüero" (grupo focal, EPMSC ERE Bucaramanga, julio de 2013) hasta la utilización de los delitos como justificadores de los malos tratos: "Nos miran como una basura. Nos llaman violos".

En conclusión, los participantes tienen claridad acerca de la edad legal a partir de la cual se considera al AM, pero esta no se concibe como un obstáculo para el desarrollo de diferentes actividades, y tomarla de esa manera les ayuda a asumir efectivamente las situaciones que se les presentan en su cotidianidad. A esto se le puede sumar la asignación de términos positivos para describir al AM asociados a la edad y las experiencias de vida, lo cual proporciona la sensación de ir un paso más adelante que los adul- 
tos más jóvenes. En este mismo orden, se encontró que asignan un gran valor a la posibilidad de poder ejecutar labores como una forma de percibir y hacer ver que son funcionales. También se distinguen casos en los que experimentan deterioro en la salud dentro de lo esperado en el proceso de envejecimiento, y en ellos, parece existir un equilibrio entre la aceptación de las consecuencias del paso del tiempo, el momento actual y los roles que les corresponden, que les ayuda a enfrentar con actitud positiva este momento. En consecuencia, identifican la dependencia como un determinante de la vejez, que ejemplifican realizando paralelos entre el cuidado que necesita un AM y el que necesita un niño.

Por último, se encuentra que anteponen la edad cuando manifiestan la necesidad de ser tratados como un grupo con necesidades especiales, dentro de las que se encuentran el buen trato, la atención médica y la posibilidad de contar con espacios exclusivos adaptados a sus condiciones y características. Todo esto, sumado a estilos de vida precedentes al encarcelamiento que son desfavorables para el desarrollo del envejecimiento, son los principales factores que representan riesgo y que deben ser intervenidos con el fin de mejorar las condiciones en las que se encuentran los AMPL.

\section{Aspectos económicos de los adultos mayores}

La población de AM en el mundo entero tiende a aumentar. Resulta importante contextualizar este desarrollo debido a que las proyecciones muestran que existe un acelerado envejecimiento demográfico de la población con edad igual o mayor a los 60 años, frente a la población total. En América Latina, el fenómeno genera mayor preocupación si se tiene en cuenta que cerca del $30 \%$ de esa población se encuentra por debajo de la línea de pobreza; incluso se considera que una proporción de ese porcentaje - cerca del $40 \%$ - se encuentra en estado de indigencia (Celade, 2010). Al respecto, es importante mencionar lo planteado por Gainzo Vicente en relación con la "emergencia" del envejecimiento: 
A pesar de ser el envejecimiento individual un proceso que ha estado presente en toda la historia de la humanidad, no es hasta el Siglo XX, que comienza a convertirse en un fenómeno social, tanto para los países con alto desarrollo económico, como para los países en desarrollo. Según datos de Naciones Unidas, en 1950 existían en el mundo 200 millones de personas mayores de 60 años, en 1975 aumentó a 350 millones, pronosticándose para el año 2020, la cifra de más de mil millones. (2009)

En este sentido, resulta contradictorio que una de las características para definir al AM sea su salida de la actividad laboral o productiva, cuando la carencia de ingresos en esa etapa de la vida es una situación que afecta a más de la mitad de estas personas en Colombia, ${ }^{4}$ y la posibilidad de que estén incluidas en el mercado laboral es muy baja, lo que trae como consecuencia la poca cobertura de la seguridad social. Al respecto, algunos AMPL mencionan que efectivamente encontraron algunas barreras para el acceso al trabajo cuando se encontraban en libertad, pero, además, mencionan un aspecto muy interesante y es el de la capacidad para seguir trabajando pese a su edad: "Yo lo que quiero es seguir trabajando hasta que sea capaz, hasta ya lo último" (grupo focal, EPMSC Bucaramanga, julio de 2013). Este deseo de continuar laborando no resulta contradictorio frente a la realidad de América Latina, donde la participación económica de las personas mayores es más elevada, sobre todo en los países más pobres, aunque sea precaria e informal en la mayoría de los casos (Cepal, 2009) (figura 7).

Esta situación que enfrentan los AM que se encuentran fuera de los EPC en sí ya es grave, pero cuando se suma el hecho de estar privados de la libertad, la situación se vuelve aún más crítica porque las instituciones creadas para la protección de esta población no se han adaptado, ni lo vienen haciendo, para dar respuesta a la tendencia de envejecimiento demográfico, y más aún cuando la esperanza de vida se encuentra en aumento.

4 De acuerdo con los datos de la Cepal, en Colombia luego de los 50 años, progresivamente se perciben $40 \%$ menos ingresos, la principal fuente de ellos son los aportes familiares y, en un menor porcentaje, la anhelada pensión o jubilación. 
Figura 7. América Latina (países seleccionados): población de 60 años y más, según fuente de ingreso, zonas urbanas

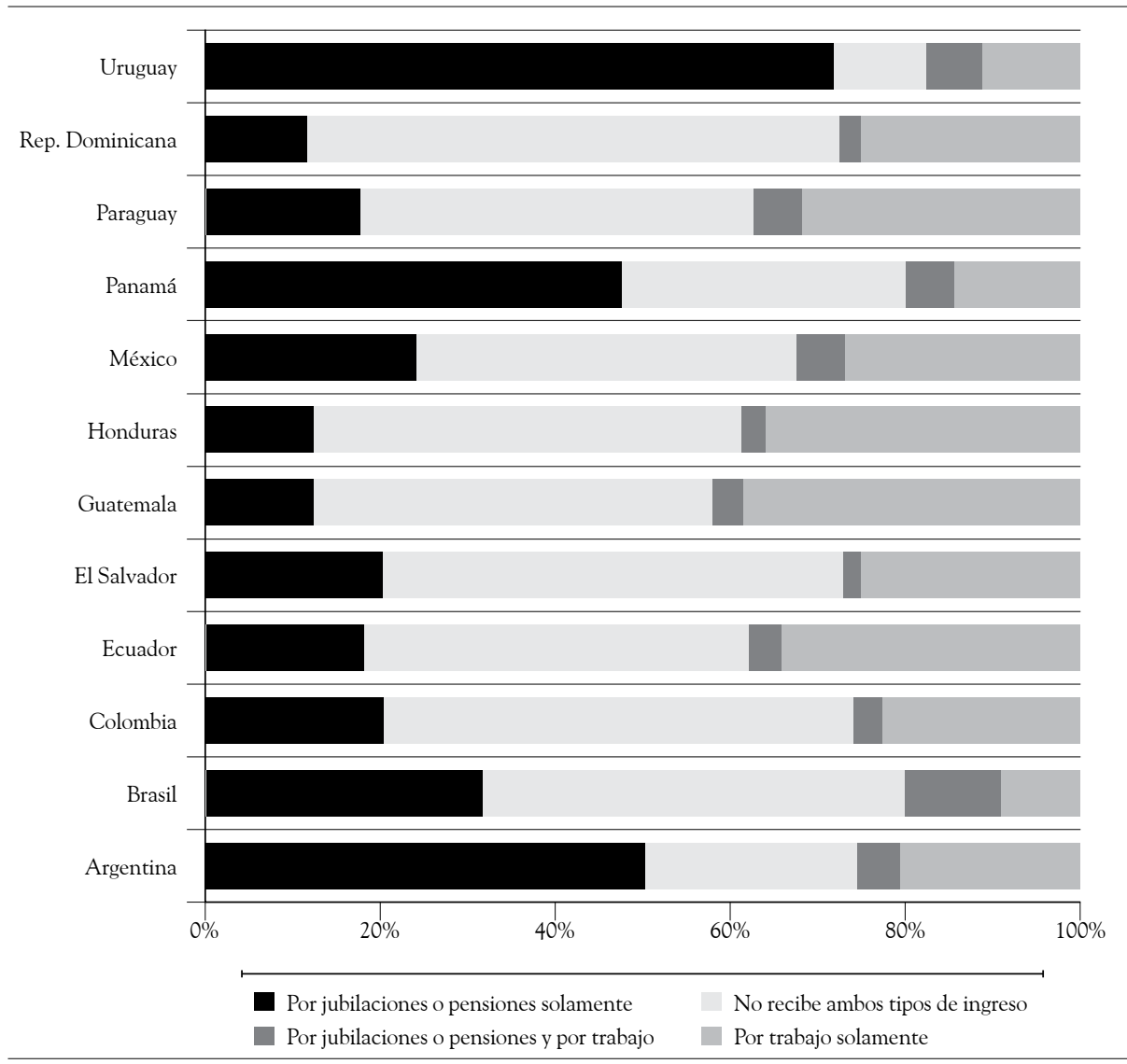

Fuente: Cepal, sobre la base de tabulaciones especiales de las encuestas de hogares de los respectivos países (Celade, 2010).

\section{Aspectos sociológicos del adulto mayor}

La construcción de las representaciones sobre la vejez varía de acuerdo con los contextos y los grupos humanos; así, se suele adjudicar cierto rol de importancia a los ancianos pertenecientes a "sociedades simples" y cierto rol de inutilidad a los ancianos en las sociedades industriales y postindustriales. Sin embargo, gracias a múltiples estudios, se ha determinado que, en todos los tiempos han habido posiciones y prácticas frente a los AM, que 
van desde la eliminación física hasta la gerontocracia (Alba, 1992). De esta manera, culturalmente se ha significado a este colectivo que, sin embargo, puede presentar como único rasgo común la edad.

Es habitual, entonces, encontrar en las sociedades primitivas la figura del patriarca, representado por el viejo de la familia, quien, en razón de su experiencia y sabiduría, era venerado y respetado. También se solía adjudicar a los más viejos ciertos poderes asociados con la magia y lo sobrenatural. En otros casos, por el contrario, como en algunas tribus nómadas, era común el exterminio de los ancianos, por considerarlos una carga difícil de llevar. Esta práctica puede asociarse también con la ocurrencia de infanticidios y la eliminación de personas con discapacidad. En Grecia y Roma la vejez se asocia a la prudencia y la sabiduría, de allí la institución del Senado. Durante la Edad Media, se impone más bien, permeada por los principios del cristianismo, la práctica de la caridad y la benevolencia hacia los ancianos desvalidos (Alba, 1992). De esta manera, no hay una concepción única sobre la vejez, ni temporal ni espacial; cada contexto desarrolló y continúa desarrollando formas de entender y abordar esta etapa de la vida.

Desde el punto de vista sociológico, para este estudio se aborda la ancianidad en términos de roles, de las representaciones sociales que se construyen a su alrededor y de la dicotomía normal-anormal. En ese sentido, se realiza un análisis de lo que socialmente se espera de un anciano, de la forma como debe comportarse y de los significados que se le atribuyen, en otras palabras, del cumplimiento de la expectativa social. Todo ello, partiendo de la hipótesis de que el AMPL es considerado dos veces "anormal": en razón de su edad, por salir del ámbito de la productividad y estar asociado a la enfermedad y la discapacidad, y en relación con la ley, por la comisión del delito.

En el primer caso, el anciano deja de producir recursos económicos porque se jubila, porque sus condiciones físicas decrecen o porque no cumple con los requisitos establecidos para el cumplimiento de ciertos trabajos; por tal motivo, es marginado y estigmatizado como un ser no productivo, "inútil" y, por tanto, prescindible. 
Este tipo de segregación cultural está en relación con la obsesión productivista propia de la "modernización" capitalista: si, como sucede en la cultura del capitalismo, a los viejos se les considera más como "jubilados" que como personas, entonces no es raro que la sociedad "adulta" segregue hacia ellos una actitud estigmatizadora y dirigista. Retiro e inutilidad quedan emparentados al ser definidos socialmente, y así, que el primero signifique también carencia en una mayoría de ocasiones resulta algo enteramente lógico. (Rodríguez-Ibañez, 1979, p. 78)

Tal vez lo más preocupante de esta segregación es la pérdida del rol o los roles que el individuo tenía anteriormente, al ser considerado como un ser improductivo y engorroso; el AM debe resignarse a una especie de muerte social, que le impide seguir desarrollándose y poner sus conocimientos y habilidades al servicio de la sociedad. Al respecto, Gainzo Vicente afirma:

Socialmente se ha considerado el rol del jubilado como un rol sin rol, por no haberle reconocido la sociedad contemporánea un papel social como lo hacían muchas sociedades primitivas o la medieval, donde el final de la actividad guerrera o artesanal no suponía la pérdida del status social. Dichas sociedades eran más eficaces en la utilización de los recursos humanos que las contemporáneas, ya que los mayores cuando dejaban una actividad encontraban otra sustitutiva, relevante para ellos y útil para la comunidad. (2009)

Sin embargo, la situación del AM varía considerablemente de acuerdo con el contexto socioeconómico en el que se desenvuelve. De esta manera, lejos de pensar en su jubilación, muchos AM deben seguir pensando en conseguir su sustento y el de su familia. Al respecto, es importante mencionar los testimonios de algunos AMPL que participaron en los grupos focales y que afirmaron vivir muy preocupados al pensar que sus familias ya no contaban con el soporte económico que ellos representaban. Al respecto, uno de ellos menciona: "Un aspecto importante con relación al AM es la falta que hay para dar una asistencia, o sea, de pronto a la familia, por ejemplo la esposa, en caso de nietos pequeños que dependen de ese AM que está detenido, 
entonces eso no lo hace una entidad, ver como este señor está aquí, pero ver también cómo está su familia afuera" (grupo focal, establecimiento EC Bogotá, La Modelo, mayo de 2013).

En este sentido, es común encontrar que en distintas sociedades, "los ancianos y las ancianas que no acceden a los beneficios de pensiones y/o jubilaciones continúan realizando actividades que desempeñaron desde jóvenes, a pesar de limitaciones físicas o del deterioro de su salud al ser muchos de ellos portadores de conocidas enfermedades endémicas" (Martínez et al., 2008, p. 79), lo que es profundamente contrastable con un hallazgo de campo, relacionado con las expectativas de vida de los internos AM, tanto hombres como mujeres, quienes -la gran mayoría- afirman que quieren salir de prisión para continuar trabajando como lo hacían antes.

Por su parte, el imaginario de enfermedad que se asocia a la adultez mayor es muy fuerte y, asimismo, la apariencia y la condición física del anciano no corresponden al estereotipo impuesto socialmente. En las sociedades actuales, nadie quiere envejecer, todo el mercado apunta a la prolongación de la juventud, lo cual se evidencia en la sobreoferta de productos como cremas antiarrugas, cirugías estéticas, gimnasios, tratamientos adelgazantes, etc. De esta manera, en razón de su edad, el anciano incumple las normas asociadas a la productividad y la estética; es, por tanto, un individuo anormal. Por otro lado, la relación entre adultez mayor y discapacidad es muy estrecha; de acuerdo con las cifras de la OMS, cerca del 15\% de la población mundial tiene algún tipo de discapacidad:

En los años futuros, la discapacidad será un motivo de preocupación aun mayor, pues su prevalencia está aumentando. Ello se debe a que la población está envejeciendo y el riesgo de discapacidad es superior entre los adultos mayores, y también el aumento mundial de enfermedades crónicas como la diabetes, las enfermedades cardiovasculares, el cáncer y los trastornos de la salud mental. (OMS, 2014)

Este vínculo entre vejez y discapacidad se asocia, a nuestro modo de ver, con el paradigma de la prescindencia desarrollado en torno a esta última, que afirma que la persona con discapacidad es innecesaria, toda 
vez que no representa mayor contribución a la sociedad. Igualmente, este paradigma abarca el modelo eugenésico, que ensalza la perfección corporal y el modelo de la marginación, lo que indica que la persona con discapacidad es objeto de exclusión, caridad y beneficencia (Velásquez, 2009, p. 8).

De esta manera, se consolida el AM como un individuo "anormal", definido desde su incapacidad productiva y desde la "imperfección" corporal. En el segundo caso planteado, es evidente que el AMPL no solo falta a la norma, sino que directamente quebranta la ley; en ese sentido e independientemente de los móviles que lo impulsan, también es un sujeto "anormal".

La violación de la ley, esta acción concreta, es de tal importancia que pone en movimiento toda la maquinaria del Estado y decide en detalle casi todo lo que ocurrirá subsecuentemente. El factor decisivo es el crimen o el delito (el pecado), no los deseos de la víctima, no las características individuales del culpable, no las circunstancias particulares de la sociedad local. (Christie, 1984, p. 60)

Así, el AMPL se consolida como un sujeto doblemente "anormal" frente a los ojos de la sociedad. Frente a la anormalidad surge una tendencia a la normalización, que ha sido denominada por Foucault como proyecto normativo (2000), y que está destinada a corregir lo imperfecto y a poner en cauce lo que se ha descarriado, en el marco de los parámetros estipulados por los discursos hegemónicos, producto de una ciencia única, reconocida y validada.

La forma en que se vincula en este estudio el concepto de AM con la anormalidad se relaciona con un discurso de corte social y económico, que se refiere principalmente a pautas físico-corporales y a la capacidad de producción. El estereotipo físico impuesto deja por fuera a las personas viejas, quienes, a causa del deterioro propio de los años, incumplen la norma y se vuelven indeseables. Por su parte, las relaciones propias del sistema económico y político en el que nos desenvolvemos, mediadas esencialmente por la producción, marginan al AM, quien ya no puede producir o no produce 
a la velocidad y con la calidad exigida, lo que lo convierte, de igual manera, en un individuo indeseable.

En este sentido, el caso del AM se ajusta también, a nuestro modo de ver, a un proyecto normativo que, en ocasiones, incluso se soluciona con el encierro (ancianatos, asilos o instituciones geriátricas). Para Arle Hochschild, este aislamiento responde a factores políticos, económicos y sociales: "El aislamiento de los ancianos se debe fundamentalmente a tres factores: su 'declive en el rendimiento laboral', la consolidación de un 'sistema de estratificación basado en la edad' y 'el relativo debilitamiento de los vínculos de parentesco' a nivel general" (citado en Rodríguez-Ibañez, 1979 , p. 81). Al indagar por el concepto de AM en los grupos focales, se encontraron las siguientes asociaciones, que en general guardan coherencia con los elementos planteados en este capítulo (tabla 8):

Tabla 8. Características asociadas al concepto de adulto mayor

\begin{tabular}{|l|l|}
\hline \multicolumn{1}{|c|}{ Concepto } & \multicolumn{1}{c|}{ Características } \\
\hline & Edad. \\
\cline { 2 - 3 } & Capacidad. \\
\cline { 2 - 3 } Adulto mayor & Vulnerabilidad. \\
\cline { 2 - 3 } & Disminución de las capacidades físicas. \\
\cline { 2 - 3 } & Ealabras otorgadas al concepto. \\
\cline { 2 - 3 } & Limitación de acceso al trabajo. \\
\cline { 2 - 3 } & Aspectos positivos. \\
\cline { 2 - 3 } & Enfoque diferencial. \\
\cline { 2 - 3 } & Actitud personal. \\
\cline { 2 - 3 } & Actitud social \\
\hline
\end{tabular}

Fuente: elaboración propia. 


\section{Edad}

La edad es la asociación inmediata que se hace al concepto de AM, casi sin excepción. AM es para los participantes una persona que ha pasado cierta edad o que tiene más de 60 o 65 años.

\section{Capacidad}

Igualmente, se hace referencia al concepto de capacidad para denotar que pese a su edad, el AM tiene plena capacidad para realizar cualquier tipo de trabajo o labor que se le encomiende: "A mí si me ponen a hacer un trabajo, yo lo hago" (grupo focal, EPMSC Acacias, mayo de 2013). Este aspecto contrasta con el imaginario de improductividad que se adjudica al AM, pues muchos de ellos manifiestan poder continuar con las labores que venían desarrollando o iniciar unas nuevas.

\section{Vulnerabilidad}

Un gran número de participantes reconocen que la edad avanzada y las condiciones que la acompañan generan vulnerabilidad; es decir, la necesidad de cuidados especiales, dependencia y desprotección. Específicamente, en el ámbito carcelario, es importante resaltar que muchos participantes afirman no ser peligrosos, precisamente por su vulnerabilidad y reclaman, por tanto, un castigo diferente a la prisión, donde se les facilite la prestación de cuidados especiales que requieren por su edad.

Al respecto, a partir de los hallazgos en campo y de otras evidencias previamente documentadas, se puede afirmar que los roles adjudicados a los ancianos pueden estar asociados al cuidado, pero en doble vía; es decir, no solo los ancianos demandan cuidados, muchas veces son ellos mismos quienes se ocupan del cuidado de otros miembros de la comunidad. 
Cuando estos (los viejos) no pueden autoabastecerse completamente, requieren el apoyo de los "nuevos" para su subsistencia. En este sentido, la solidaridad y la reciprocidad hacia los ancianos constituyen una pauta generalizada, lo que se vincularía tal vez con el protagonismo que adquieren en determinadas instancias de la crianza, socialización y cuidado de la salud de los miembros de la comunidad, no solo de los niños. (Martínez, Morgante, \& Remorini, 2008, pp. 76-77)

\section{Disminución de las capacidades físicas}

Muchos participantes reconocen una disminución de las capacidades físicas y afirman que la vejez está acompañada de achaques, limitaciones, enfermedades del cuerpo y de la mente, decaimiento y problemas de memoria, lo que implica una mayor y oportuna atención médica.

\section{Palabras otorgadas al concepto}

Los internos reconocen algunas nominaciones o palabras otorgadas al concepto de AM, como cucho o abuelo. En el ámbito carcelario, también se desarrollan apelativos como los violos, el escuadrón de la muerte o los que tienen la lápida pegada en la cola: "Nos llaman el escuadrón de la muerte... menospreciando todo el tiempo" (grupo focal, EPMSC Bucaramanga, julio de 2013). Estas palabras o apelativos se enmarcan en el ámbito de la estigmatización y se vinculan con características como chocho, caprichoso, inútil, incapaz, discapacitado e inválido: "Prácticamente uno es un inválido más que un discapacitado" (grupo focal, EC de Bogotá, La Modelo, mayo de 2013).

Realizando un comparativo, se encuentra que estas connotaciones son bastante generalizables y corresponden a sociedades industriales o postindustriales, mediadas por relaciones de tipo capitalista, en las que el viejo es considerado un demandante de servicios y, por tanto, una carga para la sociedad. 
Asociada a una idea de decadencia, de ocaso, la vejez, lejos de desearse o ponderarse, se previene. De este modo, no se procura desarrollar capacidades propias de una etapa de la vida sino desalentarla, en cuanto es negativamente considerada (soledad, incapacidad, vulnerabilidad, pérdidas, etc.). Este modelo occidental de viejo y de vejez -acompañado de una segregación etaria basada en el rechazo de alcanzar tal condición- contribuye a aumentar una imagen de los viejos demandante, como carga económica. (Martínez et al., 2008, p. 85)

\section{Limitación de acceso al trabajo}

Los estigmas traen consigo consecuencias evidentes que se materializan de diversas formas, una de ellas es la limitación de acceso al trabajo. De acuerdo con lo observado en campo, el trabajo es uno de los aspectos de la vida más importante para los AMPL, de allí que una de las preocupaciones propias de su edad radica en que son conscientes de que las oportunidades laborales disminuyen con los años y, en su caso, con el atenuante de haber estado en prisión: "Ya nos prohíben trabajar, no tenemos derecho al trabajo, que ya no nos pueden ocupar en ninguna clase de trabajo, aquí hay un código que yo lo tengo, donde dice que personas de la tercera edad, que pasen de los 60 años, no se pueden ocupar en ninguna clase de oficio pesado" (grupo focal, EPMSC Acacias, mayo de 2013).

\section{Aspectos positivos}

Sin embargo, no todas las características asociadas al concepto son negativas, algunos participantes reconocen las ventajas y los aspectos positivos de ser AM, y relacionan esta edad con el respeto, la madurez, la ejemplaridad, la experiencia, la responsabilidad y la sabiduría: "Son los que saben qué es lo que están haciendo y qué es lo que deben hacer... que tienen responsabilidad consigo mismos y con sus familias" (grupo focal de mujeres, Complejo Carcelario y Penitenciario de Jamundí, julio de 2013). Es muy interesante 
encontrar en la caracterización planteada por los participantes el aspecto de ejemplaridad, que por supuesto sería inmediatamente cuestionado por un tercero, al tratarse de los AMPL, quienes han infringido la ley o, al menos, son sospechosos de haberlo hecho. Efectivamente, en algunas sociedades, los viejos son los conocedores de la norma y, por tanto, los responsables de transmitirla a las nuevas generaciones:

Los viejos son portadores de la norma justificada que rige el orden social [...] Esta supremacía en el saber confiere a los ancianos un papel fundamental en el plano educativo, dado que transmiten a los más jóvenes la historia del grupo y las reglas sociales de que son depositarios (Martínez et al., 2008, p. 82)

\section{Enfoque diferencial}

Por otro lado, aparece el aspecto de enfoque diferencial, que es fundamental porque no hace referencia únicamente al concepto de AM, sino también a la privación de la libertad; los internos reconocen que por el hecho de tener cierta edad y estar en prisión requieren de un tratamiento especial que se adapte a sus condiciones particulares. De esta manera, se menciona constantemente la necesidad de que estos tengan un patio especial para estar aislados de las revueltas, el vicio, los abusos y el peligro; también se habla de las diferencias entre los jóvenes y los viejos, lo que dificulta la convivencia, y de la necesidad de una atención prioritaria en salud.

\section{Actitud personal y social}

Para algunos participantes, como se anotaba en los aspectos psicológicos de la vejez, esta es una cuestión mental o de actitud, independientemente de la edad que se posea, de allí que se vinculen al concepto los aspectos de actitud personal y actitud social. Respecto a esta última, los participantes afirman haber sido discriminados en razón de su edad; por este motivo, la 
vejez significa soledad, aislamiento, desprecio y rechazo. La discriminación se vive tanto fuera como dentro de la cárcel: "De pronto vienen unos artistas que cantan, pero a nosotros los viejitos no nos sacan, somos un estorbo, dicen pa' qué si esos se quedan dormidos, entonces solo sacan a los jovencitos" (grupo focal, Complejo Carcelario y Penitenciario de Jamundí, julio de 2013).

De esta manera, las definiciones y las características otorgadas al concepto de AM, en el marco de los grupos focales, se pueden ubicar, de una u otra manera, en la tipología de estrategias de acomodación a la ancianidad (Ibañez, 1979, p. 90), planteada por Suzanne Reichard, Florine Linson y Paul G. Petersen, y que establece cinco posibilidades:

- Constructividad: caracterizada por la actividad y la lucha contra el deterioro físico e intelectual.

- Dependencia: caracterizada por la pasividad y el aislamiento.

- Defensividad: caracterizada por el rechazo a la propia edad.

- Hostilidad: caracterizada por el miedo y la exaltación de la juventud.

- Odio hacia uno mismo: caracterizada por el pesimismo, la depresión y la aceptación de la muerte como alivio.

Como se puede apreciar, algunas de estas atribuciones al concepto de AM hacen referencia a la autopercepción que se tiene de la condición y otras se refieren a la percepción que tienen los otros. Surgen, así, conceptos bastante objetivos como la edad o la disminución de capacidades físicas, que se contrastan con las actitudes personales o sociales, las imputaciones prevalentemente negativas de la vejez y el reconocimiento de una condición especial. 